2021, Volume 16, ATEE 2020 - Winter Conference. Teacher Education for Promoting WellBeing in School. Suceava, 2020, pages: 518-529|

https://doi.org/10.18662/lumproc/atee2020/36

\section{Study on the}

Training Needs of Teaching Staff to Provide Quality Early Childhood Education Services

Sofia-Loredana TUDOR ${ }^{\mathbf{1}}$ Claudiu LANGA ${ }^{2}$

Adriana LAZ̆̌R3

${ }^{1}$ University of Pitesti, Pitesti, Romania

E-mail: loredana.tudor@upit.ro

${ }^{2}$ University of Pitesti, Pitesti, Romania

E-mail: claudiu.langa@upit.ro

${ }^{3}$ University of Pitesti, Pitesti, Romania

E-mail: adriana.lazar@upit.ro
Abstract: Early child development is related to early education, health, nutrition, and psychosocial development; therefore, the holistic concept of early approach combines elements from the area of stimulation of the child, bealth, nutrition, speech therapy, psychological counselling, physical development support, etc. The need for the development of integrated early education services and their extension to the area of 0-3 years are priorities of the European strategies assumed through a complex of educational policy measures, having as a priority the development of quality early education services for the benefit of all prerequisites for lowering the schooling rate (Strategy for early childhood education, Strategy for parental education, Strategy for reducing early school leaving in Romania, Study on the evaluation of public policies in the field of early childhood education - Saber Early Childhood). In this context of the development of early childhood education, numerous inequalities are identified in the implementation of European and national strategies and programs in the development of early childhood education services, supported by economic, political, social factors, etc. In order to make them compatible at European level, we consider it necessary to support training and development programs for staff providing educational services in early childhood education institutions. The purpose of this study is to acknowledge the opinion of the bodies with attributions in the prekindergarten and preschool education in Romania, as well as of the civil society and public opinion, as a prerequisite for identifying school policy measures and developing programs for training the teaching staff so as to be able to provide educational services in early childhood education (representatives responsible for early childhood education in school inspectorates and Houses of the Teaching Staff, teaching staff in preschool educational institutions, representatives of the Ministry of Labour and Social Protection, representatives of the Social Assistance Directorate, managers of nursery schools, representatives of NGOs and other categories of organizations with experience in the field, parents and interested representatives of the civil society and public opinion). The present study is a qualitative research based on the focus-group method, but also a quantitative research by using the questionnaire-based survey, being carried out on a representative sample of 100 persons (2 focus-group of 25 persons, respectively 50 persons involved in the survey-based questionnaire). The conclusions of this study highlight the need to restructure the system of early childhood education in Romania through interventions at the legislative level and ensure a unitary system of policy and intervention in early childhood education. Also, we believe it is imperative to reorganize the training system of the human resource, by developing complementary competences of the teaching staff, adapted to the training needs of the early childhood population, ensuring a valuable inclusive and integrated intervention.

Keywords: early childhood education; inclusive education; integrated system of education; training of teaching staff

How to cite: Tudor, S. -L., Langa, C., \& Lazăr, A. (2021). Study on the Training Needs of Teaching Staff to Provide Quality Early Childhood Education Services. In O. Clipa (vol. ed.), Lumen Proceedings: Vol. 16. ATEE 2020 - Winter Conference. Teacher Education for Promoting Well-Being in School. Suceava, 2020 (pp. 518-529). Iasi, Romania: LUMEN Publishing House. https://doi.org/10.18662/lumproc/atee2020/36 


\section{Introduction}

\subsection{Introduction}

Concerns regarding the development of a quality early education system have been a constant target of educational policies in the last years in order to develop the services of preschool and pre-kindergarten education adapted to the needs of care and education of the school population, with an emphasis on the disadvantaged population and social inclusion. Focusing on early education is fundamental, the theoretical and experimental studies of the last 10 years highlighting the importance of this period in the intellectual, physical, social and emotional development of the child; on the other hand, it is noticeable that the losses / delays / stagnation arising during the early development period will be difficult to recover and compensated later and with considerable investments.

\subsection{Theoretical background}

Knowing the needs of the child, respecting human rights to access and receive equal education are central elements of social policies and European legislation on adapting services to the individual needs of children, their growing families and the communities to which they belong (Boyden \& Levison, 2000). International studies highlight the need to develop services for early childhood as a premise for reducing the negative effects of socioeconomic disadvantages, through education for young children, by facilitating families' access to basic services and social participation. (OECD, 2006) Adopting the curriculum and methodology appropriate to childhood education, and the appropriate organization of direct and indirect educational influences (Vrăşmaş, 2002), ensuring the legislative framework and staffing, as well as developing partnership policies with the family and social protection and health services offered in nurseries or day centres, family, in kindergartens and primary schools, in recreational programs, etc. represent the indispensable pillars for the provision of quality services (Tassoni et al., 2005) and the grounds of the principles of inclusive early education.

Defined as the period of a child's life from birth to the age of eight, early childhood includes services for preschool children and for children in the first years of school (UNICEF \& WHO, 2012). From the perspective of lifelong learning (Păun \& Iucu, 2002) early education "identifies the beginning of development", including all forms of support or care necessary for the very young child to understand his right to survival, protection and our care to ensure its development. (Evans et al., 2000) Educational services are fundamental, and education needs to be approached from related 
perspectives - care, nutrition, health, protection, stimulation and development - through the holistic approach to the development of the child's personality in the family, community, regional, global environment, to ensure its well-being. The well-being of the child, as a goal of early education, is conditioned by the indispensable quality of health, nutrition, education, parental support, social protection, and prevention of risks in the child's development (UNESCO, 2014). In most countries that have developed educational services and policies for early education, the child's well-being is analysed from the perspective of a holistic approach to the emotional, personal and social development, physical development, artistic skills and language and communication skills, understanding the world, cooperation skills and health education. (European Commission/EACEA, 2019, p. 13) Educational policies in the field of early education are based on the following values and principles: promoting and practicing a child-centred education and its global development, in the context of interaction with the natural and social environment; avoidance of discriminatory expressions and prejudices by teachers, non-teaching staff, children and parents; promoting and applying the principles of social inclusion; taking into account the specific individual educational needs of children; focusing educational efforts on the needs of families in order to create a close partnership with them, including parental participation in organizing and conducting activities.

Early childhood education is the "childhood project" in which childhood and the child are explored (Pulkkinen, 2002, as cited in Hujala, 2008 , p. 21), the period that brings significant added value to the child, providing a variety of learning stimuli and a group community of learning, in which the child can develop his/her own social capital. Conti and Heckman (2014 as cited in Warren et al., 2016, p. 1), analysing the effects from the point of view of productivity, argue the need for complementary early interventions in the development of the future adult - investments in social services, educational services provided by the school and investments in services that ensure a quality growth of the child.

In recent studies on the transition from early to primary education, early education regulates "arrangements that provide education and care for children on birth to compulsory primary school age in integrated systems" (OECD, 2017, p. 18), because an quality early education prepares the child for school and for life, with several relevant indicators: the balance between what the child learns and how much the child learns, how each child learns according to individual learning needs, training of educators for early education, flexibility of community interventions, school and family, collaboration based on respect and mutual support between educational policy makers, managers, parents, other educational factors. (OECD, 2017, 
pp. 19-21) Pedagogical approaches are intertwined with those in the psychological area to identify a balance between cognitive and non-cognitive development, by integrating play activities or non-formal activities. (Hencke \& Knoll, 2014)

The field of studies on early childhood has reached the point where the practice of professional development and knowledge requires in-depth theoretical and empirical expertise to guide the implementation of the necessary educational reforms in the context of expanding services. (Sheridan et al., 2009, p. 378) European Education Policy Guidelines (EURLex, 2006) accept that efficiency and equity should be integrated prospectively into lifelong learning strategies given the effects of investment in long-term education and training. (EUR-Lex, 2006) In this context, early education reform must include: early intervention programs to support the most disadvantaged individuals; various intervention measures, such as foreign language learning or support for children's social adjustment; educational programs adapted to the preschool period (specifics of learning at an early age, individual and social skills, improving the offer of educators, parental commitment, etc.); special parental education programs to stimulate parental engagement; education and integration programs for marginalized people.

There is a need to develop strategies for investing in early childhood education, which in turn will generate long-term benefits for themselves, their families and the nation. (Steven \& Ackerman, 2006, p. 97) Integration of as many children as possible: the number of children who could benefit from what was stated above is analysed from the perspective of a varied set of social, economic, cultural, educational variables, etc., of which the financial investment in the development of quality programs and investment in the training of specialized personnel.

\section{Research questions/Aims of the research}

The purpose of this study is to acknowledge the opinion of the bodies with attributions in the pre-kindergarten and preschool education in Romania, as well as of the civil society and public opinion, as a prerequisite for identifying school policy measures and developing programs for training the teaching staff so as to be able to provide educational services in early childhood education.

The objectives of this study focus on: O1. identifying the opinion of the representatives of the social community regarding the type of system and the categories of services necessary for the development of early education in Romania; O2. analysis of the point of view of the representatives of the 
social community on the routes of initial and continuous training of the specialist for early education; O3. analysis of the opinion of the representatives of the educational community regarding the need to restructure the early education system in Romania by identifying the weaknesses / threats of the current system.

\section{Research methods}

\subsection{Participants}

The present study is a qualitative research based on the focus-group method, but also a quantitative research by using the questionnaire-based survey, being carried out on a representative sample of 100 persons ( 2 focusgroups of 25 persons, respectively 50 persons involved in the survey-based questionnaire).

Fifty representatives participated in the focus groups, as follows: stakeholders responsible for early childhood education in school inspectorates and Houses of the Teaching Staff, teaching staff in preschool educational institutions, representatives of the Ministry of Labour and Social Protection, representatives of the Social Assistance Directorate, managers of nursery schools, representatives of NGOs and other categories of organizations with experience in the field, parents and interested representatives of the civil society and public opinion.

The social survey based on a written questionnaire was answered by 275 teachers from preschool education in the South Muntenia area (Bucharest, Ilfov, Arges, Teleorman, Brasov, Olt, etc.) described by the variables gender, age and teaching experience.

\subsection{Materials and instruments}

In order to carry out the social survey through focus group, an interview guide was built, requesting the participants' opinions on: the type of system for which Romania should opt in the implementation of early education (a unitary system, in which children aged 0-6 year olds to be in the same type of institution, with the governance of a central authority, as a system leader or a fragmented system, with different institutions for children under 3 and for those over 3, with different governance; the categories of services that should be offered to children from birth to 6 years, the categories of staff involved in early childhood education and care (ECEC), the flexible training routes for staff involved in ECEC.

Starting from the topic investigated, the questionnaire was developed as a conceptual tool, resulting from the decomposition of the phenomenon studied in the following dimensions: SWOT analysis of the early education 
system in Romania, and the quality of human resources with responsibilities in early education (teachers, family, and community).

\subsection{Procedure}

The survey through the group-focused interview was addressed to the representatives of the institutions from the social community with responsibilities in raising, protecting and educating the child. 2 focus groups were organized, by sending invitations to participate to social representatives from neighbouring counties, in the cities of Pitesti (Argeş, Vâlcea, Olt, Dolj, Teleorman, Gorj counties - 1 educator / preschool inspector, 1 representative of the DSP (Department of Public Health), 1 representative of APL (Local Public Administration) / county, 1 representative of parents /NGOs with relevant assets and 1 project representative) and Braşov (counties Braşov, Alba, Sibiu, Mehedinți, Harghita - 1 educator / preschool inspector, 1 representative of DSP, 1 representative of APL / county, 1 representative of parents /NGOs with relevant assets, plus 1 representative of university and 1 representative of pedagogical high school from BV and 3 project representatives). The activity was carried out by recruiting participants who meet the eligibility criteria, communicating with participants who responded to the invitation to participate in the focus group and collecting their opinions using the interview guide.

From a methodological point of view, throughout our research study, we used the questionnaire-based survey as a method of quantitative scientific research. The elaboration of the data collection tool took into account the characteristics of the target group, has been done in the form of a structured questionnaire for teachers in preschool education. The questionnaires were administered through Google forms, and the data obtained were statistically processed in tables of results and represented graphically. Subsequently, they will be interpreted both from a quantitative and qualitative perspective, offering certain directions and perspectives on the significance and evolution of the researched aspects.

\section{Results}

\subsection{Results}

\section{The results obtained by conducting the social survey through focus group}

The information processing was performed following three questions addressed to the participants and the answers provided by them, by categories / types of institutions / professionals. 
Item 1: Institution responsible for providing education and early care services for children from birth to 6 years and the type of system (integrated or separate)

The focus group significantly highlighted different opinions of social representatives from representatives of the education system. All participants support the need for a unitary system, for a unitary vision, regardless of whether or not the institutions operate in the same location. Unitary financing and human resource management employed by an entity are elements that will contribute to the optimization of the early education system from an organizational, functional point of view. There is also a lack of educational staff in nursery schools, discussing possible interventions for human resource development - either with childcare educators or with specialists in early education.

Item 2: Types of services that should be offered to children from birth to 6 years (standard, standard and alternatives, only alternatives)

Participants express their opinion for complementary services, both standard services (nursery, kindergarten) and alternative services (play centres, playgroups, etc.). It is also recommended that resource centres for parents developed in kindergartens provide parenting services (including courses on topics tailored to the needs of children and children).

Item 3: Categories of staff involved in early childhood education and care, level of education required, institution (s) responsible for the initial and continuing training of teachers for early education, flexible training routes for teachers, in the context of current legislation and the real need of the system

Representatives of educational institutions reiterate the quality of initial training through pedagogical high schools, a training structure that currently operates in few areas of the country and offers a small number of graduates specializing in childcare. Other opinions support university-level training through 2 possible routes: expanding the competency profile of teachers for preschool education by participating in continuing education programs or developing a new specialization for the profession of specialist in early education. The second training route will be able to be implemented only in the conditions of some legislative modifications by including the profession in the Nomenclature of occupations in Romania, but also by restructuring at the level of university specializations.

\section{The results obtained by conducting the social survey based on a questionnaire}

This survey involved 275 respondents from the South-Muntenia area (Bucharest, Ilfov, Arges, Teleorman, Brasov, Olt) of which only 2 males. From the distribution of respondents by age categories we identify that in the sample of respondents $62.28 \%$ of the total respondents are between 38 48 years old, $28 \%$ between $48-58$ years old, so their teaching experience is 
relevant to the results present needs analysis (Table 1). In terms of seniority, most of the sample of subjects is over 20 years old $(72 \%)$. (Table 2 )

Table 1

\begin{tabular}{lllllllll}
\hline \multicolumn{1}{c}{ Age } & \multicolumn{1}{c}{$\begin{array}{c}\text { Length of professional } \\
\text { experience }\end{array}$} \\
\hline $18-28$ & $28-38$ & $38-48$ & $48-58$ & $58-68-5$ & $5-10$ & $10-15$ & $15-20$ & over 20 \\
\hline 20 & 81 & 109 & 49 & 1629 & 21 & 52 & 47 & 126 \\
\hline $11,42 \%$ & $46,28 \%$ & $62,28 \%$ & $28 \%$ & $9,14 \%, 57 \%$ & $12 \%$ & $29,71 \%$ & $26,85 \%$ & $72 \%$
\end{tabular}

Source: Authors research

Source: Authors research

The current early education system is characterized by the following variables: the very large number of children enrolled in a group (over 30 children, although the education law provides a maximum of 25 preschoolers), a significant number of school population with special educational needs, material resources from kindergartens not meeting the requirements of a quality early education, the absence of investment in early education, a high degree of bureaucratization of the whole system, the lack of administrative and curricular continuity given that, although most nurseries operate in kindergartens, their administration is done by another administrative body (Ministry of Labour).

The opinions put forward by the respondents in favour of the need to reform the human resource in the early education system are: practicing a child-centred education ( $23 \%$ consider it very important), designing educational activities closely related to the age peculiarities of children $(26 \%$ consider it very important), the development of the educational partnership with the family (28\% consider it very important), the adaptation to the changes in the educational environment ( $28 \%$ consider it very important), the need for continuous training ( $21 \%$ consider it very important).

Respondents' opinions on the need for early integration and institutionalization of the child are outlined in the following weaknesses /threats of the current early education system in Romania: the growing number of children with special educational needs; the social needs of children to adapt to the community, to optimize communication skills, to identify large gaps between developmental rhythms, especially language disorders; the entry of children into the community without having acquired skills specific to the basic age, each having particular needs, the presence of aggressive manifestations as premises for the early development of bullying behaviours.

Regarding the teaching staff, the sensitive variables of the system are: the lack of continuous training courses in the pre / preschool field, especially in rural areas; lack of support staff for children with SEN; insufficient 
information and lack of involvement of institutional management for the adoption of coherent strategies for the development of the early education system.

The most intense threats to the system are, from the respondents' point of view, representatives of the family and the community, which exert basic influences and services in early childhood. Among the most highlighted opinions we mention: the lack of offers of parental counselling in the field of early education, non-involvement of parents in the educational environment and in supporting an inclusive education and their difficult adaptation to educational changes; increasing family abandonment through social and professional migration of parents abroad, parents do not accept children's problems (where appropriate), there is no mutual support (community-kindergarten; kindergarten-family, disinterest on the part of parents, poverty).

\section{Discussions}

O1. The opinion of the representatives of the social community regarding the type of system and the categories of services necessary for the development of early education in Romania.

The social representatives express their conception regarding the existence of a unitary system of early education, by integrating preschool children in the educational institution. At the same time, they express the difficulties of moving to this system in terms of lack of certification of teachers' skills for early preschool education, insufficient material resources and not adapted to the training needs of preschool children.

O2. The point of view of the representatives of the social community on the routes of initial and continuous training of the specialist for early education.

The perception of social representatives on the various staff training routes for early education is not unitary. The different training routes through pedagogical high schools with a childcare profile (secondary education), through university colleges of teachers (short-term studies), through the faculties of education sciences or through other university specializations recognized by transferable credits (higher education) - have created inequalities financial, but also different educational approaches and concepts.

O3. The opinion of the representatives of the educational community regarding the need to restructure the early education system in Romania by identifying the weaknesses / threats of the current system. 
From the quantification of the opinions of the teachers participating in this study, we can describe some aspects that characterize the early education system in Romania, highlighting the training needs of teachers: legislative inconsistencies regarding the initial and continuous training of teachers, insufficient training of specialists for early education, insufficient investments in the early education system and in the system of continuous training of human resources, the need to change the conception about the education and institutionalization of the child in educational institutions starting with the age of 2 , the need for collaboration between specialists from different areas to ensure quality educational services.

\section{Conclusions}

Awareness of the crucial importance of childhood for the further development of the child has been the basis for policies on the development of quality early education services. Education in this age period involves ensuring a secure physical and emotional environment, stimulating cognitively and socially for all children, regardless of gender, ethnicity, background, religion. For these reasons, the need to professionalize teachers who carry out educational activities for young children is a fundamental one. On the other hand, it is necessary to set up multidisciplinary teams of specialists for the development of quality services in early childhood education (teacher for early education, speech therapist, psychologist, counsellor, mediator, nutritionist, nurse, social worker, etc.).

Changing the conception of education and the educational needs of children in the first years of life explains the new conception on the essence of the education process that will achieve a holistic approach to early development by combining elements of areas of child stimulation, health, nutrition, early education, as well as development of community and women.

The educational offer adapted to the needs of training and development of the child during early childhood must be receptive to the needs of all those involved in this system:

- for the specialist in early education: participation and involvement; continuous reception of the new; empathy; communicability; opening; flexibility;

- for the institutions responsible for educational policies: awareness of educational policies that regulate the role of early education in the European institutions, development of educational policies that offer equal opportunities for early education for children from different and disadvantaged backgrounds, 
- for the family: awareness of the role of equal and equitable partner in the educational process; developing new parenting skills (tolerance, acceptance of the child as he/she is).

- for society: awareness, acceptance and respect for children's rights; opening up opportunities for the development of early education institutions in small communities.

\section{References}

Boyden, J., \& Levison, D. (2000). Children as Economic and Social Actors in the Development Process. EGDI, Working Paper, 1.

EUR-Lex. (2006). Eficiența şi echitatea sistemelor europene de educație și formare. Comunicarea Comisiei către Consiliul şi Parlamentul European din 8 septembrie. Brussels. Report No.: COM/2006/0481 final. https://eurlex.europa.eu/legal-content/RO/TXT/?uri=celex\%3A52006DC0481

European Commission/EACEA. (2019). Eurydice Brief. Key Data on Early Childhood Education and Care in Europe. Office of the European Union.

Evans, J. L., Meyers, R. G., \& Ilfeld, E. (2000). Early Childhood Counts, A Programing Guide on Early Childhood Care for Development. World Bank Institute.

Hencke, J., \& Knoll, S. (2014). Early childhood education study. ECES Progress Report. International Association for the Evaluation of Educational Achievement. https://www.iea.nl/publications/presentations/early-childhood-educationstudy

Hujala, E. (2008). The Development of Early Childhood Education as an Academic Discipline in Finland. Nordic Early Childhood Education Research, I, 17-23.

OECD. (2006). Report Starting Strong II: Early Childhood Education and Care. http://www.oecd.org/education/school/startingstrongiiearlychildhoodedu cationandcare.htm

OECD. (2017). Starting Stronf V: Transition from Early Childhood Education and Care to Primary Education. OECD Publishing. https://www.oecdilibrary.org/education/starting-strong-v 9789264276253-en

Păun, E., \& Iucu, R. (Coord.). (2002). Educația preşcolară în România. Editura Polirom.

Sheridan, S. M., Edwards, C. P., Marvin, C. A., \& Knoche, L. L. (2009). Professional Development in Early Childhood Programs: Process Issues and Research Needs. Early Education and Development, 20(3), 377-401.

Steven, W. B., \& Ackerman, D. J. (2006). Costs, Benefits, and Long-Term Effects of Early Care and Education Programs: Recommendations and Cautions for Community Developers. COMMUNITY DEVELOPMENT: Journal of the Community Development Society, 37(2), 86-100. 
Tassoni, P., Beith, K., \& Bulman, K. (2005). NVQ Level 2 Children's Care, Learning and Development: Candidate Handbook. Heinemann Educational Publishers.

UNESCO. (2014). Holistic Early Childhood Development Index (HECDI) Framework. UNICEF \& WHO. (2012). Care for child development: Participant manual. WHO.

Vrăşmaş, E. (2002). Educația timpurie a copiilor. Editura Polirom.

Warren, D., O'Connor, M., Smart, D., Edwards, B. (2016). A Critical Review of the Early Childhood Literature. Australian Institute of Family Studies. 